\title{
Preparation of Zein Microspheres Conjugated with Antitumor Drugs Available for Selective Cancer Chemotherapy and Development of a Simple Colorimetric Determination of Drugs in Microspheres
}

\author{
Toshio Suzuki, ${ }^{*, a}$ Etsuko Sato, ${ }^{a}$ Yasuyuki Matsuda, ${ }^{a}$ Hitoshi Tada, ${ }^{a}$ Katsuo Unno, ${ }^{a}$ and Tetsuro Kato ${ }^{b}$ \\ Department of Pharmaceutical Science, Akita University Hospital, ${ }^{a}$ and Department of Urology, ${ }^{b}$ School of Medicine, Akita University, Hondo 1-1-1, Akita \\ 010, Japan. Received September 19, 1988
}

\begin{abstract}
Zein microspheres conjugated with antitumor drugs (mitomycinc (MMC), daunomycin hydrochloride (DM), peplomycin sulfate (PEP)) were prepared by using a dimethyl sulfoxide (DMSO)- $\mathrm{H}_{2} \mathrm{O}$ system. MMC with low solubility in $\mathrm{H}_{2} \mathrm{O}$ was easily entrapped by the standard procedure, whereas some modifications were required for moderately and highly soluble drugs such as DM and PEP.

Colorimetric determination of the drugs in microspheres was easily achieved by use of the phenol-sulfuric acid method for drugs with sugar moieties in their molecules, such as DM and PEP, while a simple treatment of the microspheres with concentrated sulfuric acid was applied in the case of drugs having a chromophore in their molecules, such as DM and MMC.
\end{abstract}

Keywords anticancer drug-zein microsphere; selective cancer chemotherapy; dimethylsulfoxide- $\mathrm{H}_{2} \mathrm{O}$ system; biodegradable protein; colorimetric determination; phenol-sulfuric acid method; concentrated sulfuric acid

The major problems in cancer chemotherapy are the toxic drug effects on normal cells and the rapid clearance of the drug from tumor tissues. Efforts have, therefore, been directed towards increasing the drug selectivity by means of selective drug administration into the tumor-feeding arteries, ${ }^{1,2)}$ optimized dose scheduling based on cell cycle specificity, ${ }^{3)}$ or multimodal chemotherapy with combinations of various kind of drugs. Recent advances in drug delivery systems have indicated that certain modifications of dosage forms may improve the efficiency of cancer chemotherapy. ${ }^{4)}$ Numerous polymeric materials have been investigated as biodegradable carriers, including polylactic acid, ${ }^{5)}$ polycaprolactone, ${ }^{6)}$ polydioxane, ${ }^{7)}$ polyalkyl-Zcyanoacrylate, ${ }^{8,9)}$ and heat-denatured or chemically denatured aggregated albumin. ${ }^{10 \text { ) }}$

Recently, Kato and his co-workers ${ }^{11,12)}$ introduced selective arterial chemoembolization as an effective modality of treatment utilizing microcapsule-entrapped antitumor drugs. This approach, however, has the disadvantage that it damages normal tissue surrounding the tumor, since relatively large microcapsules (mean $250 \mu \mathrm{m}$ ) have been used. It also has the disadvantage that it requires experience in the technique of catheterization and its use is limited to tumors which are accessible by catheter.

With these disadvantages in mind, we attempted to develop microspheres of suitable size for selective chemoembolization or phagocytosis by macrophages which are predominantly present in the inflammatory tissue or the tumor stroma using readily available zein as a biodegradable carrier. In order to test the efficiency of our procedure for the preparation of microspheres, we chose mitomycin C (MMC), daunomycin hydrochloride (DM) and peplomycin sulfate (PEP) as prototype drugs which were not soluble, fairly soluble and extremely soluble in water, respectively. The procedure described herein is entirely different from previous methods in which the entrapment efficiency of the drug in the matrix was limited by the drug's solubility in water, ranging from 0.35 to $15 \%$. In addition, our procedure should be useful for the preparation of microspheres of both hydrophilic and hydrophobic drugs.

Determination of recovery of the drugs in microspheres is another problem when a protein is used as the matrix. In usual eases, multiple steps and tedious procedures such as destruction of the matrix by an enzyme followed by extraction of the drug with some organic solvent and then measurement by ultraviolet spectroscopy or high-pressure liquid chromatography are required. Use of these techniques may not be reliable because of interference by the enzyme and degradation products (amino acids).

To overcome these problems, we tried to develop a simple procedure for the measurement of drugs in microspheres. Colorimetric determination of drugs in microspheres was easily achieved by use of the phenol-sulfuric acid method $^{13)}$ for drugs containing sugar moieties in their molecules, such as PEP and DM, while a simple treatment of the microspheres with concentrated sulfuric acid was suitable in the case of drugs having a chromophore in their molecules, such as DM and MMC.

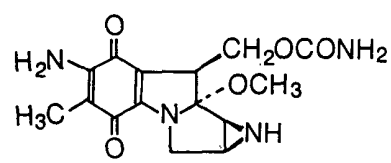

mitomycin $\mathrm{C}(\mathrm{MMC})$

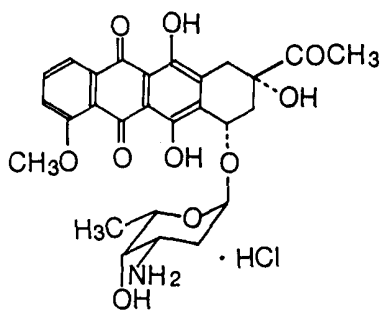

daunomycin hydrochloride (DM)

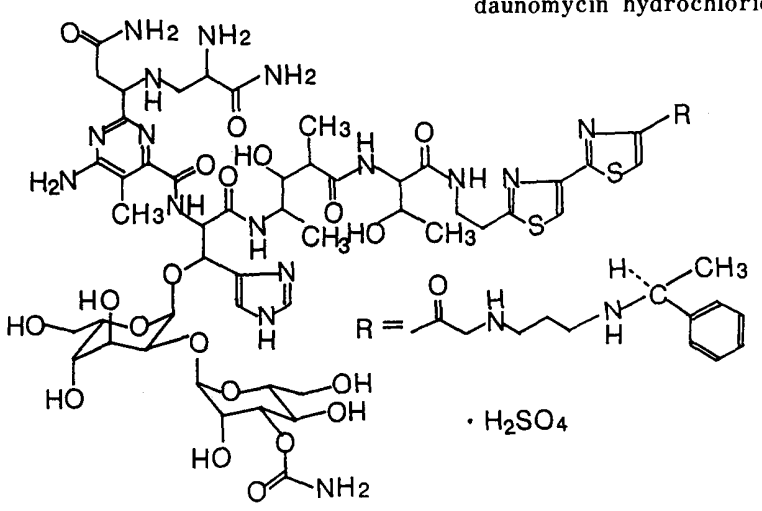

peplomycin sulfate (PEP)

Chart 1 


\section{Experimental}

Materials MMC and DM were kindly supplied by Kyowa Hakko Co., Ltd. PEP was supplied by Nippon Kayaku Co., Ltd. Zein, 20\% (w/w) glutaraldehyde, dimethyl sulfoxide (DMSO) and polyvinylpyrrolidone (PVP) were purchased from Katayama Industries, Ltd., Maruishi Pharmacy, Ltd., Wako Pure Chemical Industries, Ltd., and Nakarai Chemical Ltd., Japan, respectively. $N, N$-Dimethylaminopyridine (DMAP), trimethylsilyl chloride and imidazole were obtained from Aldrich Chemical Company Inc., U.S.A.

Procedure for Preparations of Anticancer Drug-Zein Microspheres Method 1: A $10 \mu \mathrm{l}$ aliquot of $20 \%(\mathrm{w} / \mathrm{w})$ aqueous glutaraldehyde was added to a solution of $10 \mathrm{mg}$ of MMC or PEP in $0.25 \mathrm{ml}$ of DMSO and the mixture was stirred for $1 \mathrm{~h}$ at room temperature. Then $20 \mathrm{mg}$ of zein was added, the mixture was stirred for an additional $1 \mathrm{~h}$, and $10 \mathrm{ml}$ of $2 \%(w / w)$ aqueous solution of PVP was poured in all at once. The reaction solution was vigorously stirred for $24 \mathrm{~h}$. The resulting emulsion action solution was vigorously stirred for $24 \mathrm{~h}$. The resulting emulsion The obtained microspheres were washed three times with distilled water. During washing, the microspheres were centrifuged at $10000 \mathrm{rpm}$ for $20 \mathrm{~min}$, the supernatant was discarded, and the pellet was resuspended. Ultrasonication at $35 \mathrm{~W}$ followed by lyophilization of the pellet provided MMC-zein or PEP-zein microspheres as shown in Table I. Alteration of the ratio of $\mathrm{MMC}$ to zein (from $1: 1$ to $1: 3$ ) increased the recovery of drugs by $20.7 \%$.

Method 2: A $10 \mu$ laliquot of $20 \%(\mathrm{w} / \mathrm{w})$ aqueous glutaraldehyde was added to a solution of $10 \mathrm{mg}$ of DM or PEP in $0.25 \mathrm{ml}$ of DMSO and the mixture was stirred for $1 \mathrm{~h}$ at room temperature. Then $20 \mathrm{mg}$ of zein and $2 \mathrm{mg}$ of DMAP were added, the mixture was stirred for an additional $1 \mathrm{~h}$, and $10 \mathrm{ml}$ of $2 \%(\mathrm{w} / \mathrm{v})$ aqueous solution of PVP was added all ance. The reaction solution was vigorously stirred for $24 \mathrm{~h}$. The resulting emulsion was centrifuged at $10000 \mathrm{rpm}$ for $20 \mathrm{~min}$ and the supernatant was discarded. The same treatment as that described in method 1 provided DMzein and PEP-zein microspheres as shown in Table 1 .

TABLE I. Characterization of Various Microspheres Prepared by Methods 1,2 and 3

\begin{tabular}{|c|c|c|c|c|c|c|}
\hline \multicolumn{3}{|c|}{ Weight of substrates } & \multirow{2}{*}{ Methods } & \multirow{2}{*}{$\begin{array}{c}\text { Weight } \\
\text { of } \mathrm{MS}^{a)} \\
(\mathrm{mg})\end{array}$} & \multirow{2}{*}{$\begin{array}{l}\text { Recovery } \\
\text { of drugs } \\
\text { (mg) }\end{array}$} & \multirow{2}{*}{$\begin{array}{l}\text { Uptake of } \\
\text { drugs into } \\
\operatorname{MS}^{b)}(\%)\end{array}$} \\
\hline Drug (n & & Zein (mg) & & & & \\
\hline \multirow[t]{2}{*}{ MMC } & 10 & 20 & 1 & 20.3 & 6.1 & 30.0 \\
\hline & 20 & 60 & 1 & 99.7 & 16.3 & 16.4 \\
\hline DM & 10 & 20 & 2 & 26.2 & 8.2 & 31.3 \\
\hline \multirow[t]{3}{*}{ PEP } & 10 & 20 & 1 & 17.1 & 1.3 & 7.6 \\
\hline & 10 & 20 & 2 & 24.4 & 4.5 & 18.4 \\
\hline & 20 & 40 & 3 & 79.6 & 15.1 & 19.0 \\
\hline
\end{tabular}

a) MS: microspheres. b) Uptake of drugs into MS was calculated by means of the following equation: $\frac{\text { recovery of drugs }(\mathrm{mg})}{\text { weight of } \mathrm{MS}(\mathrm{mg})} \times 100$.

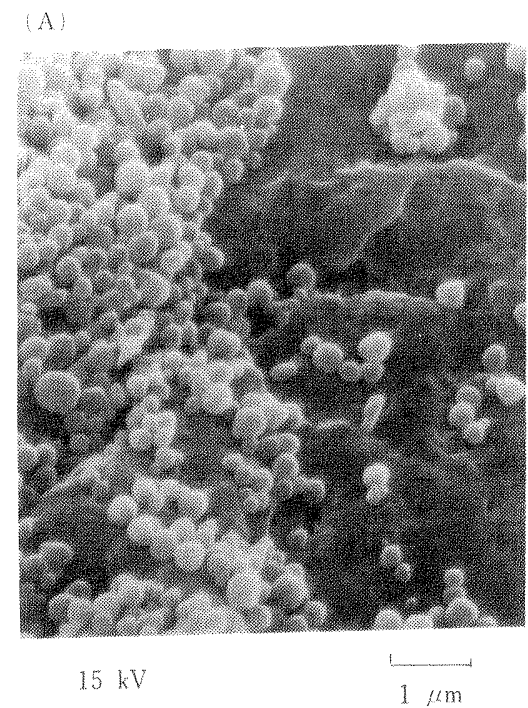

Method 3. Trimethylsilyl chloride $(32.3 \mu \mathrm{l})$ was added to a mixture of $20 \mathrm{mg}$ of PEP and $26 \mathrm{mg}$ of imidazole. This mixture was stirred for $40 \mathrm{~min}$ at room temperature, then $40 \mathrm{mg}$ of zein was added and stirring was continued for an additional $10 \mathrm{~min}$. Next, a $2 \%(\mathrm{w} / \mathrm{w})$ aqueous solution of PVP was poured all at once into the above solution and the whole was vigorously stirred for $24 \mathrm{~h}$. Centrifugation of the resulting emulsion, washing of the pellet with distilled water, ultrasonication, and then lyophilization afforded PEP-zein microspheres as summarized in Table 1 .

Colorimetric Determination of the Drugs in Microspheres Procedure

1. A $0.05 \mathrm{ml}$ aliquot of $80 \%$ phenol was added to a suspension of $2 \mathrm{mg}$ of the microspheres in $2 \mathrm{ml}$ of distilled water and then $5 \mathrm{ml}$ of concentrated sulfuric acid was rapidly added. During this procedure, the microspheres were easily hydrolyzed and dissolved. The mixture was allowed to stand for $10 \mathrm{~min}$, and then it was shaken and placed for $20 \mathrm{~min}$ in a water bath at $30 \mathrm{C}$. The absorbance of the characteristic color was then measured at $490 \mathrm{~nm}$ for PEP and $579 \mathrm{~nm}$ for DM.

Procedure 2: Concentrated sulfuric acid $(5 \mathrm{ml})$ was added to suspension of $2 \mathrm{mg}$ of microspheres. The mixture was allowed to stand for $10 \mathrm{~min}$, and then it was shaken and placed for $20 \mathrm{~min}$ in a water bath at $30^{\circ} \mathrm{C}$. The absorbance was measured at $490 \mathrm{~nm}$ for DM and $374 \mathrm{~nm}$ for MMC.

\section{Results and Discussion}

Characterization of Anticancer Drug-Zein Microspheres Prepared by Various Procedures Table I shows the properties of microspheres prepared under various conditions. As can be seen in Table I, satisfactory results were obtained in each case. The microspheres of a drug with low solubility in $\mathrm{H}_{2} \mathrm{O}$ [MMC $0.3 \%$ (w/w)] were easily prepared using the standard method developed by us ${ }^{14)}$ (method 1), whereas some modifications were required for the fairly soluble or highly water-soluble materials, DM and PEP. Simple treatment of the salt of the drug with DMAP (method 2) provided $81.8 \%$ recovery for DM and $44.7 \%$ for PEP $(12.6 \%$ in method 1$)$. These results clearly indicate that decrease of the hydrophilicity of the drug increases the recovery.

Thus, treatment of PEP with an excess of imidazole

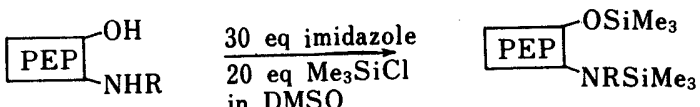

$$
\begin{aligned}
& \text { in DMSO }
\end{aligned}
$$

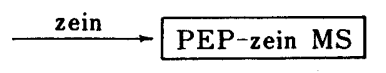

Chart 2

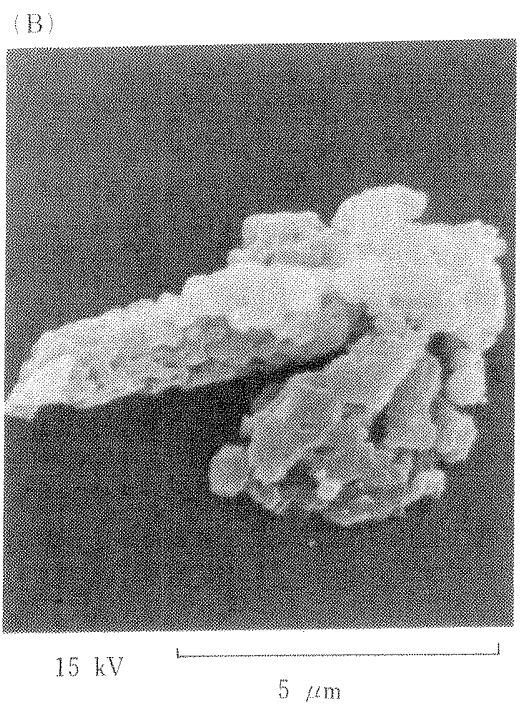

Fig. 1. Scanning Electron Micrographs of MMC-Zein Microspheres in Mono-dispersed Form (A) and Aggregated Form (B) 
(30 eq) and trimethylsilyl chloride (20 eq) in DMSO resulted in the formation of the polyprotected trimethylsilyl PEP, the protecting groups of which could be easily removed under almost neutral conditions (Chart 2). By the use of this modification, the recovery of PEP has been increased to $75.6 \%$.

Physical Properties of Microspheres Entrapping Antitumor Drugs Scanning electron micrographs of the MMC microspheres are shown in Fig. 1 and the particle size distribution is shown in Fig. 2 as an example. Although the particles after lyophilization are considerably aggregated, sonication in distilled water readily allows them to monodisperse. The surfaces of both the monodispersed and aggregated forms were observed by scanning electron microscopy. (Fig. 1) The former consisted of regularly shaped particles with a diameter of less than $1 \mu \mathrm{m}$ which would be suitable for the phagocytosis by macrophages, while the latter consisted of rough and invaginated particles which would be suitable for chemoembolization. The particle size

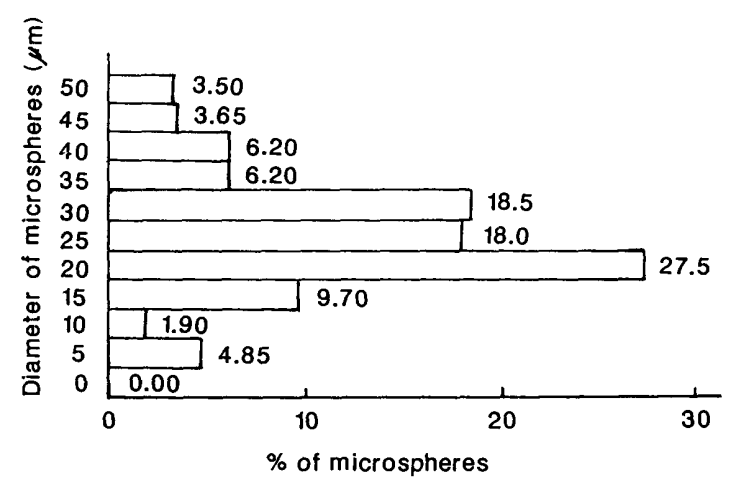

Fig. 2. Particle Size and Distribution of MMC-Zein Microspheres of the aggregated form measured with micron photosizer ranged from 5 to $50 \mu \mathrm{m}$, as shown in Fig. 2.

A) Absorption Curves The absorption curves of DM, PEP, and MMC obtained by plotting absorbance vs. wavelength under various conditions are shown in Fig. 3. DM in sulfuric acid has an absorption maximum at $579 \mathrm{~nm}$ as a result of both a significant bathochromic shift and a hyperchromic effect due to cleavage of the glycoside followed by dehydration, as shown in Chart 3, whereas in phenol-sulfuric acid method a new absorption maximum was seen at $653 \mathrm{~nm}$ in addition to that at $579 \mathrm{~nm}$. On the other hand, MMC in sulfuric acid has an absorption maximum at $374 \mathrm{~nm}$ due to both a slight bathochromic shift and a considerable hypochromic effect. The colors produced were unusually stable, and possessed a specific absorption peak. The amount of color produced at a constant phenol concentration was proportional to the amount of drug present.

B) Standard Curve Typical standard curves of MMC, DM, PEP and zein for each procedure are shown in Fig. 4. The standard curves obtained by plotting the drug concentration $v s$. absorption were highly reproducible. It was also confirmed that the presence of zein did not interfere with the colorimetric determination of drugs at 374,490 , and $579 \mathrm{~nm}$.

The procedures described herein allow extremely simple and reliable colorimetric determinations of various drugs in microspheres, using inexpensive, stable, and readily available reagents.

\section{Conclusion}

The procedures described herein could be applied to a variety of drugs regardless of their solubility, although

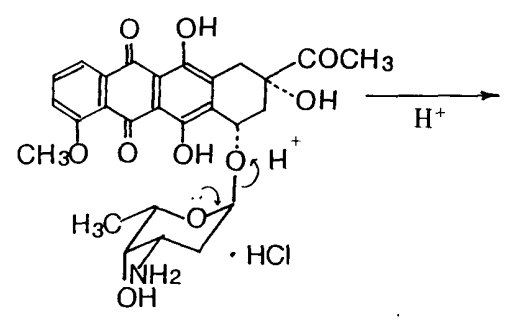<smiles>[R6]c1cccc2c1C(=O)c1c(O)c3c(c(O)c1C2=O)C[C@@](O)(C(=O)O)C[C@H]3O</smiles>

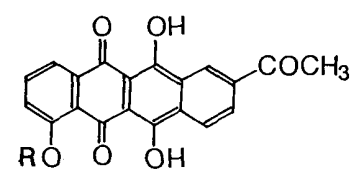

$\mathrm{R}=\mathrm{H}$ or $\mathrm{R}=\mathrm{CH}_{3}$

Chart 3

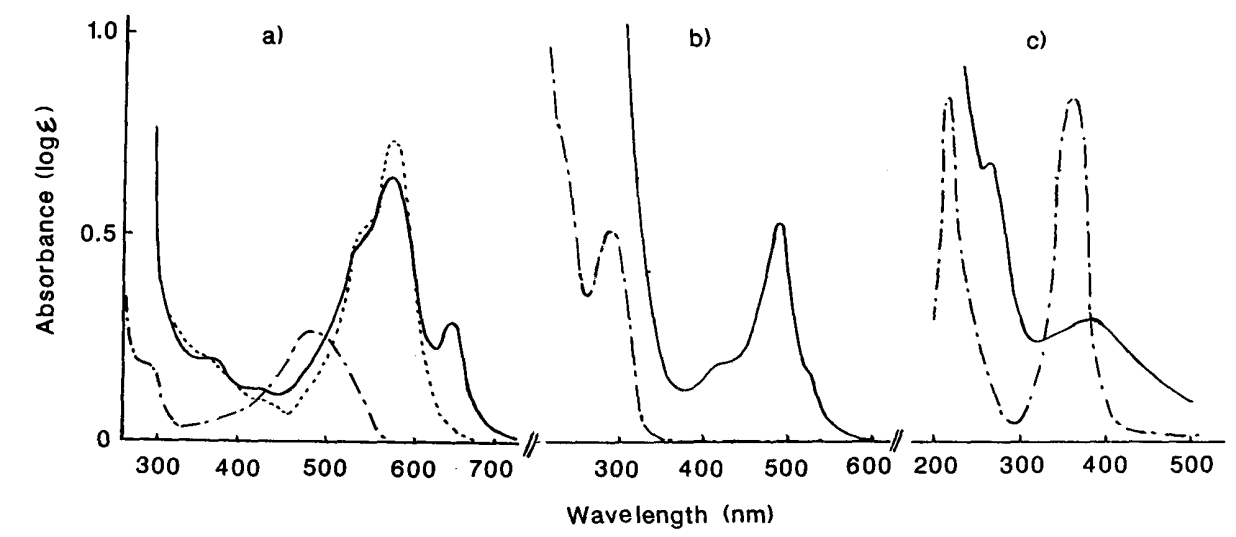

Fig. 3. Absorption Curves of DM, PEP and MMC under Various Conditions

a) - - DM $/ \mathrm{H}_{2} \mathrm{O}(200 \mu \mathrm{g} / 7 \mathrm{ml}) ; \ldots-\ldots, \mathrm{DM} / \mathrm{H}_{2} \mathrm{O}(200 \mu \mathrm{g} / 2 \mathrm{ml})$ in sulfuric acid $(5 \mathrm{ml}) ;-\frac{\mathrm{DM}}{\mathrm{O}} / \mathrm{H}_{2} \mathrm{O}(200 \mu \mathrm{g} / 2 \mathrm{ml}) \mathrm{in} 80 \% \mathrm{phenol} / \mathrm{sulfuric}$ acid $\left.(0.05 \mathrm{ml} / 5 \mathrm{ml}) ; \mathrm{b}\right)---$, $\mathrm{PEP} / \mathrm{H}_{2} \mathrm{O}(400 \mu \mathrm{g} / 7 \mathrm{ml}) ;-, \mathrm{PEP} / \mathrm{H}_{2} \mathrm{O}(400 \mu \mathrm{g} / 2 \mathrm{ml})$ in $80 \%$ phenol $/ \mathrm{sulfuric}$ acid $\left.(0.05 \mathrm{ml} / 5 \mathrm{ml}) ; \mathrm{c}\right)-\cdots, \mathrm{MMC} / \mathrm{H}_{2} \mathrm{O}(100 \mu \mathrm{g} / 7 \mathrm{ml}) ;-, \mathrm{MMC} / \mathrm{H}_{2} \mathrm{O}(100 \mu \mathrm{g} / 2 \mathrm{ml})$ in sulfuric acid $(5 \mathrm{ml})$. 


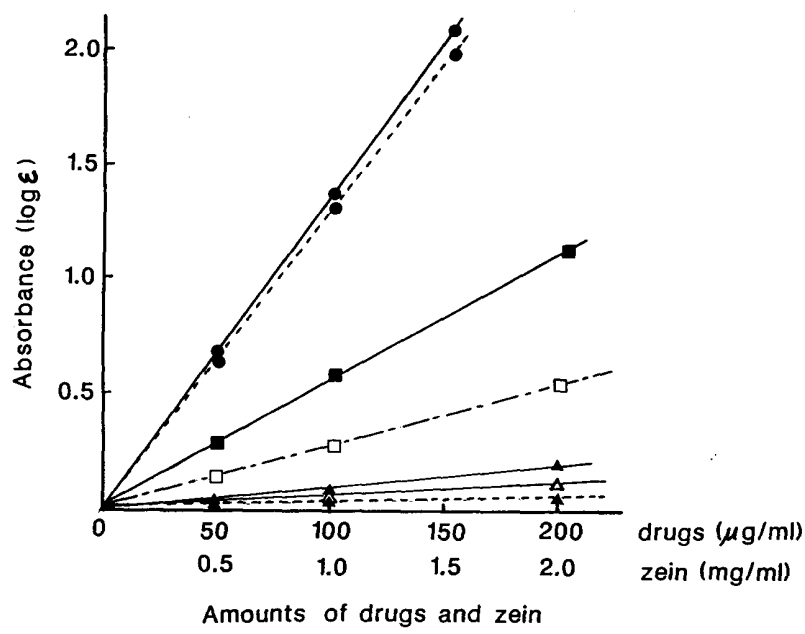

Fig. 4. Standard Curves

- DM in sulfuric acid at $490 \mathrm{~nm}, r=0.9999 ;---$, DM in $80 \%$ phenolsulfuric acid at $490 \mathrm{~nm}, r=0.9999 ;-\square-$ MMC in sulfuric acid at $374 \mathrm{~nm}, r=$ $0.9970 ;--\square--$, PEP in $80 \%$ phenol-sulfuric acid at $490 \mathrm{~nm}, r=0.9998 ;-\Delta-$, zein in sulfuric acid at $374 \mathrm{~nm}, r=0.9983 ;-\triangle-$, zein in $80 \%$ phenol-sulfuric acid at $490 \mathrm{~nm}, r=1.0000 ;---\Delta--$, zein in $80 \%$ phenol-sulfuric acid at $579 \mathrm{~nm}, r=0.9960$

some modifications are required for hydrophilic drugs. Since the sustained-release property of zein microspheres is known, ${ }^{14)}$ the aggregated microspheres would be useful for selective chemoembolization, while monodispersed microspheres would also be useful for selective cancer chemotherapy by oral or intratumoral administration based on phagocytosis by macrophages which predominantly exist in the tumor stroma. ${ }^{14)}$
Quantitative analysis of drugs in protein microspheres is usually troublesome because of the interference caused by amino acids formed by the degradative enzyme, or the enzyme itself. However, the colorimetric determination of the drugs which we have developed is extremely simple and provides a reliable result without using any expensive reagent.

\section{References}

1) C. T. Klopp, C. Alford, J. Batenan, N. Berry, and T. Winship, Ann. Surg., 132, 811 (1950).

2) E. Watkins, Jr., A. M. Khazei, and K. S. Nahra, Surg. Gynecol. Obstet., 130, 581 (1970).

3) H. E. Skipper, Cancer, 28, 1479 (1971).

4) "Methods in Enzymology," Vol. 112, ed. by R. J. Widder and R Green, Academic Press, Inc., 1985 and references cited therein.

5) D. L. Wise, T. D. Fellmann, J. E. Sanderson, and R. L. Wentworth "Drug Carriers in Biology and Medicine," ed. by G. Gregoriadis, Academic Press, Inc., 1979, p. 237.

6) C. G. Pitt, A. R. Jeffcoat, R. A. Zweidinger, and A. Schindler, J. Biomed. Mater. Res., 13, 497 (1979).

7) N. Doddi, C. C. Versfelt, and D. Wasserman, U. S. Patent 4052988 (1977).

8) A. T. Florence, T. L. Whateley, and D. A. Wood, J. Pharm. Pharmacol., 31, 422 (1979).

9) P. Couvreur, B. Kante, M. Roland, and P. Speiser, J. Pharm. Sci., 68 1521 (1979).

10) P. A. Kramer, J. Pharm. Sci., 63, 1646 (1974).

11) T. Kato and R. Nemoto, Proc. Jpn. Acad., 54, 413 (1978).

12) T. Kato, R. Nemoto, H. Mori, and I. Kumagai, Cancer, 46, 14 (1980)

13) M. Dubois, K. A. Gilles, J. K. Hamilton, P. A. Rebens, and F. Smith, Anal. Chem., 28, 350 (1956).

14) Y. Matsuda, T. Suzuki, E. Sato, M. Sato, S. Koizumi, K. Unno, T. Kato, and K. Nakai, Chem. Pharm. Bull., in press. 